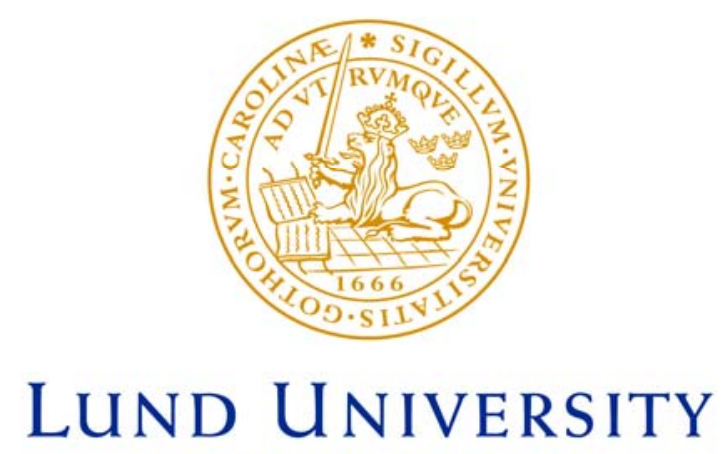

Faculty of Medicine

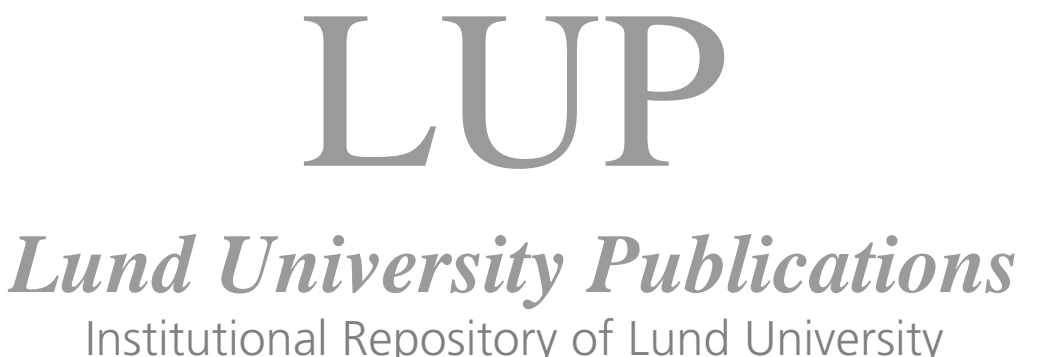

This is an author produced version of a paper published in European journal of applied physiology. This paper has been peer-reviewed but does not include the final publisher proof-corrections or journal pagination.

Citation for the published paper:

Susanna Stenevi, Robin Daly, Christian Lindén, Per Gärdsell, Magnus Karlsson

Effects of a daily school based physical activity intervention program on muscle development in prepubertal girls.

European journal of applied physiology, 2008, Issue: Nov 19

http://dx.doi.org/10.1007/s00421-008-0932-2

Access to the published version may

require journal subscription.

Published with permission from: Springer 


\title{
Effects of a Daily School Based Physical Activity Intervention Program on Muscle Development
}

\section{in Pre-Pubertal Girls}

Running Title: Physical activity and muscle development

\author{
Susanna Stenevi-Lundgren ${ }^{1}$ \\ Robin M. Daly ${ }^{2}$ \\ Christian Lindén ${ }^{1}$ \\ Per Gärdsell, ${ }^{1}$ \\ Magnus K. Karlsson, ${ }^{1}$
}

\begin{abstract}
${ }^{1}$ Clinical and Molecular Osteoporosis Research Unit, Department of Clinical Sciences, Lund University, Lund, SWEDEN and Department of Orthopaedics, Malmö University Hospital, SE 20502 Malmö, SWEDEN and ${ }^{2}$ Department of Medicine, The University of Melbourne (RMH/WH), Western Hospital, Footscray, Melbourne, AUSTRALIA
\end{abstract}

\section{Address for correspondence}

Robin M. Daly, PhD

Department of Medicine (RMH/WH)

University of Melbourne, Western Hospital

Footscray, Melbourne, AUSTRALIA 3011

Phone: +61-3-8345 6924; Fax +61-3-9318 1157; E-mail: rdaly@unimelb.edu.au 


\begin{abstract}
This 12-month prospective controlled intervention evaluated the effect of a general school-based physical activity program on muscle strength, physical performance and body composition in prepubertal girls. Fifty three girls aged 7-9 years involved in a school-based exercise program [40 $\mathrm{min} / \mathrm{d}$ of general physical activity per school day (200 min/week)] were compared with 50 agematched girls who participated in the general Swedish physical education curriculum (mean 60 min/week). Body composition (DXA), isokinetic peak torque (PT) of the knee extensors and flexors at 60 and 180deg/sec, and vertical jump height (VJH) were assessed at baseline and 12 months. The annual gain in weight was similar between the groups, but there was a greater increase in total body and regional lean mass $(\mathrm{p}<0.05)$ and fat mass $(\mathrm{p}<0.01)$ in the exercise group. Mean gains in knee extensor PT at 60 and $180 \mathrm{deg} / \mathrm{sec}$ were 7.0 to $7.6 \%$ greater in the exercise group (p ranging $<0.05$ $<0.001)$. No significant differences were detected in VJH. In conclusion, increasing school-based physical education to at least $3 \mathrm{~h} /$ week provides a feasible strategy to enhance the development of muscle strength and lean mass in pre-pubertal girls.
\end{abstract}

Key words: school based intervention, physical activity, body composition, muscle strength, vertical jump height. 


\section{Introduction}

Regular participation in physical activity or organised sports training during childhood and adolescence is regarded as an important lifestyle factor to improve musculoskeletal health, fitness and body composition. Cross-sectional and longitudinal studies of young athletes participating in a variety of moderate to high impact weight-bearing sports have reported that bone mass is up to $40 \%$ greater at loaded skeletal sites compared with less active children (Bass et al. 1998; Matthews et al. 2006). It has also been shown that young athletes and children involved in higher levels of physical activity have greater muscle mass, strength and endurance (Baxter-Jones et al. 2008; Ellenbecker et al. 2006; Kanehisa et al. 2006; Morris et al. 1997), and reduced fat mass (Dencker et al. 2006; Morris et al. 1997). In recent years, a number of school based exercise intervention trials have also shown that a range of moderate to high impact weight-bearing activities can enhance bone mineral accrual in preand/or peri- pubertal boys and girls (Bradney et al. 1998; Fuchs et al. 2001; Linden et al. 2007; MacKelvie et al. 2003; Mackelvie et al. 2001; MacKelvie et al. 2004; Morris et al. 1997;

Valdimarsson et al. 2006). Similarly, short term progressive resistance training programs in boys and girls performed two to three times per week have been shown to improve muscle strength, muscle mass and physical performance (Faigenbaum et al. 1999; Ramsay et al. 1990; Weltman et al. 1986). While these studies provide important information with regard to the potential beneficial effects of specially designed exercise programs on musculoskeletal health in selected groups of children and adolescents, it remains uncertain whether less structured and more general moderate intensity physical activity programs in a population based cohort can also improve muscle mass and performance outcomes during growth.

It is generally accepted that an increase in muscle mass and strength during growth is an important part of any child's overall physical fitness, but there are also a number of other health-related benefits that may be associated with improvements in muscular health and function. For instance, the health benefits of resistance training in children are reported to be similar to those in adults and include: improved strength, power, muscular endurance, bone density, and strength at tendon-bone interface, in 
addition to improved physical performance, self-satisfaction, self-esteem and body image (Sothern et al. 1999). There is also data indicating that exercise-induced gains in muscle strength and lean mass during growth may enhance bone mineral accrual, which could increase peak bone mass and thus reduce the risk of osteoporosis and fractures later in life (Daly et al. 2004; Morris et al. 1997).

This study was designed to evaluate whether a moderate intensity general physical activity intervention that can be readily incorporated into the school curriculum could improve bone health outcomes in young school aged girls. A secondary aim was to evaluate the effects of the intervention on body composition, muscle strength and physical performance. We recently reported that this intervention was effective for enhancing bone mineral accrual at the lumbar spine in both boys and girls aged 7 to 9 years over 12 months (Linden et al. 2007; Valdimarsson et al. 2006). Therefore, the aim of this study was to evaluate whether the same moderate intensity school based physical activity program could improve total body and regional lean tissue mass and fat mass, lower extremity muscle strength and physical performance in pre-pubertal girls.

\section{Materials and Methods}

\section{Subjects and Design}

As previously reported (Linden et al. 2007; Valdimarsson et al. 2006), The Malmö Pediatric

Osteoporosis Prevention (POP) Study, is a prospective controlled exercise intervention study designed to annually assess skeletal and muscle development in young children when they commence school. Baseline measurements in the intervention group were performed in August and September 1999, just after school started and before the exercise intervention commenced. All follow-up evaluations were carried out during the same months one year later. The controls were first evaluated in November and December with all follow-up measurements performed during the same months but two years later. We accepted a two year follow-up in the controls, as data in the literature have shown that growth in bone mass and muscle mass and strength tends to occur in a linear fashion during the prepubertal period (Kanehisa et al. 1995; Linden et al. 2007; Young et al. 2001; Zanchetta et al. 1995), an approach that has been accepted in previous publications (Linden et al. 2007; Valdimarsson et al. 
2006). During the summer period, the intervention group (and controls) had a break for 9 weeks where no additional exercise training was provided. From these data we calculated and compared the annual changes (per 365 days) in the measured parameters.

Details on the recruitment procedures and characteristics of the girls have been described previously (Valdimarsson et al. 2006). Briefly, all girls in grades 1 and 2 in one school in a middle-class area in Malmö, Sweden, chosen as the intervention school, were invited to participate in the study. Of the 61 girls, 55 agreed to participate (90\% inclusion). One girl was excluded, as she was 11 months younger than the second-youngest girl. At follow-up, one girl declined participation, leaving 53 girls with a mean \pm SD age of $7.7 \pm 0.6$ years (range $6.5-8.7$ ) at baseline. The controls were volunteers from three neighbouring schools in areas with a similar socioeconomic background to the intervention group. Sixty-four girls participated at baseline, whereas at follow-up 13 of the girls had moved out of the region or declined further participation. One girl was excluded due to treatment with growth hormone, leaving 50 controls with a mean age of $7.9 \pm 0.6$ years (range $6.8-8.9$ ) at baseline. All participants were healthy Caucasian girls not taking any medication known to influence bone or muscle metabolism. Informed written consent was obtained from parents or guardians prior to participation. The study was approved by the Ethics Committee of Lund University and the Radiographic Committee at Malmö University Hospital, Malmö, Sweden. The Swedish Data Inspection Board approved the data collection and the setup of the database.

\section{Exercise intervention}

The exercise intervention consisted of the ordinary physical activity used within the Swedish school physical education (PE) curriculum, supervised by school teachers (PE and classroom teachers), but increased to 40 minutes per day (total 200 minutes per week). This duration was chosen in order to maximise a range of health related benefits beyond just bone mass which has been shown to respond to shorter bouts of weight-bearing exercise (Fuchs et al. 2001;MacKelvie, 2003 \#45; Mackelvie et al. 2001; MacKelvie et al. 2004). Thus, no additional resources or costs were required to implement the intervention, which included personal, financial and spatial resources. The intervention school 
modified its curriculum by increasing the number of PE classes; in other words, we did not choose a school that already had a high level of physical activity for its pupils and the only direct modification of the school curriculum was the increased duration of physical activity. No other regular healthrelated modifications were performed. This approach to minimize additional resources provided the opportunity for any school to implement our program. Importantly, the PE classes did not consist of any programs specifically designed to enhance muscle and bone mass or strength. Instead, the classes included both indoor and outdoor general physical activities, such as a variety of ball games (eg. basketball, handball, soccer), running, jumping, and climbing activities (eg. tag, rope climbing, and gymnastics related activities on various apparatus). The teachers also aimed to conduct a variety of physical activities, so as not to bore the children with repeated standardized activities. This was done with the aim of minimizing the dropouts in the long term, which is reported to occur frequently in other exercise intervention studies (Bass et al. 2003). In the control schools, the same type of physical activities were used as in the intervention school, but at a level within the compulsory Swedish school curriculum of physical education, consisting of approximately 60 minutes per week.

\section{Lifestyle questionnaire}

A questionnaire, previously used and described in several studies and modified for children (Duppe et al. 1997), evaluated lifestyle factors such as socioeconomic and ethnic background, diseases, medications, fractures, consumption of dairy products, exclusion of anything in the diet, and physical activity in school and during leisure time (organised physical activity outside of school). All questionnaires were completed by the parents in consultation with the girls. Organised physical activity outside of school was calculated as the weekly time spent in organised physical activity (h/week).

\section{Anthropometry and Pubertal Assessment}

Body weight was measured with an electric scale to the nearest $0.1 \mathrm{~kg}$ and height by a wall-tapered height meter to the nearest $0.5 \mathrm{~cm}$ with the children dressed in light clothes with no shoes. Body mass index (BMI) was calculated as weight $/$ height ${ }^{2}\left(\mathrm{~kg} / \mathrm{m}^{2}\right)$. Tanner staging assessed by the research nurse 
was used to assess the maturity status of the girls. All girls were classified as prepubertal (Tanner stage 1) at baseline and follow-up.

\section{Body composition (lean mass and fat mass)}

Total body and regional lean tissue mass and fat mass (kg) were measured by dual-energy X-ray absorptiometry (DXA, DPX-L version 1.3z, Lunar ${ }^{\circledR}$, Madison, WI). All scans were performed by two trained technicians. Arm and leg lean tissue mass and fat mass were derived from the total body scan. The arm region included the hand, forearm and upper arm, which was separated from the trunk by a line positioned through the scapulo-humeral joint. The leg region included the foot, lower leg and thigh, which was separated from the pelvis by two separate lines, which were angled through the femoral neck. The technicians in our research group performed all the measurements and analysed all the scans. The precision, evaluated by duplicate measurements in 13 healthy children aged between 7 and 15 years (mean age 10 years), was 3.7\% for total body fat mass and 1.5\% for total body lean tissue mass.

\section{Physical performance (vertical jump height)}

Vertical jump height (VJH), which is a measure of neuromuscular performance, was used to assess the influence of physical activity on physical performance. The vertical jump test was performed on an electronic mat connected to a digital timer that registered the total time in the air (Product name "Time It”; Eleiko Sport ${ }^{\circledR}$, Halmstad, Sweden). From this data, the height of the jump in centimetres was automatically calculated from the computer included in the standard equipment. All vertical jumps were performed from a standing position, and participants were first required to jump onto the mat with both feet, and then make a maximal vertical jump. Each subject performed three vertical jumps from which the highest jump $(\mathrm{cm})$ was recorded. The intra-individual test variability, evaluated as the coefficient of variation for repeated measurements in 21 children, was 5.9\%. 


\section{Muscle strength (isokinetic peak torque)}

Isokinetic peak torque of the right knee extensors and flexors were evaluated by a computerized dynamometer (Biodex System 3®). Two experienced physiotherapists performed all measurements. During the testing, all participants were seated with their hips flexed to $85^{\circ}$ from the anatomical position. The axis of the knee was aligned with the Biodex axis of rotation. The participants were secured in the chair according to the standard Biodex procedure using shin, thigh, pelvic and upper crossing torso stabilization straps. When required, a $10 \mathrm{~cm}$ thick pad was used to fill the space between the participants back and the support of the chair. When the lever arm of the Biodex was longer than the lower leg of the participant a small pad was used to adjust for the difference. All participants were instructed to place their arms across their chest during the testing. The knee was positioned at $90^{\circ}$ of flexion and went through a $75^{\circ}$ range of motion, stopping at $15^{\circ}$ of flexion. Concentric isokinetic knee extension and flexion peak torque was tested at an angular velocity of 60 and $180 \%$ sec. After two submaximal warm-up repetitions, five maximal repetitions (flexion and extension) at $60^{\circ} / \mathrm{sec}$ were performed. After 30 seconds rest, this was followed by 10 maximal repetitions at $180^{\circ} / \mathrm{sec}$ for both flexion and extension, with the highest peak torque $(\mathrm{Nm})$ recorded for all measurements. All subjects received both visual and verbal encouragement during the test, a method that has proved to be more effective than using none or only one of these approaches (De Ste Croix et al. 2003). Peak torque (Nm) at both 60 and 180\% sec for extension $\left(\mathrm{PT}_{\mathrm{Ex} 60} ; \mathrm{PT}_{\mathrm{Ex} 180}\right)$ and flexion $\left(\mathrm{PT}_{\mathrm{Fl} 60} ; \mathrm{PT}_{\mathrm{F} 1180}\right)$ were normalized to body weight $(\mathrm{kg})$ and expressed as $\mathrm{Nm} / \mathrm{kg}$. The intraindividual test variability, evaluated as the coefficient of variation for repeated measurements in 21 children, was $6.6 \%$ for $\mathrm{PT}_{\mathrm{Ex} 60}, 12.1 \%$ for $\mathrm{PT}_{\mathrm{F} 160}, 12.3 \%$ for $\mathrm{PT}_{\mathrm{Ex} 180}, 9.1 \%$ for $\mathrm{PT}_{\mathrm{F} 1180}$.

\section{Drop-out analyses}

In order to ascertain whether there was any selection bias at baseline, we compared height, weight and BMI of the girls who took part in the study with those who refused to participate. Based on data from school records, there were no significant differences at baseline for any of these parameters in girls who participated in the study and those who refused to take part. For the girls that did join the study, 
the mean values for height, weight, and BMI were $126.5 \mathrm{~cm}, 26.3 \mathrm{~kg}$, and $16.3 \mathrm{~kg} / \mathrm{m}^{2}$, respectively, whereas the corresponding values for the non-participants were $127.0 \mathrm{~cm}, 26.3 \mathrm{~kg}$, and $16.2 \mathrm{~kg} / \mathrm{m}^{2}$ (pvalues $0.61,0.95$, and 0.65 , respectively). Similarly, there were no differences in baseline age, height, weight, total body or regional body composition, muscle strength or vertical jump height between the girls that completed the study and those that dropped out.

\section{Statistical Analysis}

To evaluate the influence of the exercise intervention on changes in body composition, muscle strength and VJH, all data for both groups were converted into annual changes according to the following formula: [(follow-up - baseline measurement)/duration of follow-up] and expressed as the absolute or percentage change from baseline. ANCOVA was then used to compare the annual changes for all measurements between the intervention and control group. Age and muscle strength (or VJH) at baseline, organised physical activity outside of school at follow-up, and the annual increment in total or regional lean tissue mass (or fat mass) were included as covariates. Pearson’s correlation coefficients were used to examine the relationship between the annual absolute changes in body composition, muscle strength and performance with the total mean duration of physical activity (school P.E and organised physical activity outside of school) at baseline and at follow-up divided by two.

In this study we expected to be able to identify a minimal detectable difference of $0.123 \mathrm{Nm} / \mathrm{kg}$ in the annual change in muscle strength $\left(\mathrm{PT}_{\mathrm{Ex60}}\right)$ with $80 \%$ power and an alpha level of 0.05 . There are several reasons why $\mathrm{PT}_{\mathrm{Ex} 60}$ was chosen as our primary muscle force outcome. First, there is some evidence for a greater absolute increase in knee extensor compared to flexor muscle strength from age 9 to 21 years (De Ste Croix et al. 1999). Thus, we hypothesized that increased physical activity would enhance the growth-related changes in knee extensor strength (more than flexor strength). Second, in prepubertal boys it has been reported that exercise training leads to greater relative increases in knee extensor compared to flexor peak torque (Malina et al. 2004). Finally, $\mathrm{PT}_{\mathrm{Ex60}}$ is the most precise of all the isokinetic strength tests in children. 


\section{Results}

There were no differences in the baseline anthropometric or body composition characteristics between the intervention and control group (Table 1). However, all baseline peak torque indices (Nm or $\mathrm{Nm} / \mathrm{kg}$ ) and VJH were greater in the controls (p ranging 0.06 to $<0.001$ ). Hours per week participation in organised physical activity outside of school was greater in the control compared to intervention group at baseline ( $1.3 \pm 1.6$ versus $0.7 \pm 1.2$ hours/week, $\mathrm{p}=0.055)$ and follow-up ( $1.9 \pm 1.9$ versus 1.1 \pm 1.3 hours/week, $\mathrm{p}<0.05$ ). However, as expected, total physical activity (school curriculum plus outside school) was greater in the intervention group throughout the study ( $4.4 \pm 1.3$ versus $2.9 \pm 1.9$ hours/week, $\mathrm{p}<0.05$ ). As previously reported, there were no other differences between the two groups for socioeconomic and ethnic background, chronic diseases, history of fractures or other lifestyle characteristics (medication use, dairy product consumption, and exclusion of anything in the diet) (Valdimarsson et al. 2006).

During the study period, the annual rate of gain in height and weight were similar between the groups, but there was a greater increase in total body and regional lean tissue mass and fat mass in the intervention group (Table 1). After adjusting for baseline age and peak torque, and organised physical activity outside of school at follow-up, the annual changes in all peak torque indices (in Nm) were significantly greater in the intervention group. When peak torque was normalized to body weight, only the annual increase in knee extension peak torque $\left(\mathrm{PT}_{\mathrm{Ex60}}\right.$ and $\left.\mathrm{PT}_{\mathrm{Ex} 180}\right)$ was significantly greater $(7.0$ to 7.6\%) in the intervention group (Table 1 and Figure 1); the changes in knee flexion peak torque $\left(\mathrm{PT}_{\mathrm{F} 160}\right.$ and $\mathrm{PT}_{\mathrm{F} 1180}$ ) and $\mathrm{VJH}$ tended to be greater in the exercise compared to control groups, but the between group differences were not significant. All these results remained unchanged if the annual gains in total body (or regional) lean tissue mass or fat mass were included as covariates (data not shown). The total duration of physical activity during the study period for all girls was weakly correlated with the annual absolute gains in $\mathrm{PT}_{\mathrm{F} 160}(\mathrm{r}=0.20, \mathrm{p}<0.05), \mathrm{PT}_{\mathrm{Ex} 180}(\mathrm{r}=0.24, \mathrm{p}<0.05)$, and $\mathrm{PT}_{\mathrm{F} 1180}(\mathrm{r}=0.21$, $\mathrm{p}<0.05$ ); there was also a trend for a significant relationship with $\mathrm{VJH}$ and $\mathrm{PT}_{\mathrm{Ex} 60}$ (both $\mathrm{r}=0.18$, $\mathrm{p}=0.07)$. 


\section{Discussion}

The findings from this 12 month prospective controlled school based exercise intervention indicate that increasing the amount of general moderate intensity physical education in the school curriculum from 60 to 200 minutes per week was associated with an increase in lower limb peak muscle strength and lean tissue mass in pre-pubertal girls. These findings have important clinical and public health implications because they provide evidence-based data to support the benefits of school based physical activity as an effective strategy to enhance musculoskeletal health in prepubertal girls.

Maximizing musculoskeletal health during growth, including bone density, muscle mass and strength, is recognized to play an important role in reducing the risk of a number of chronic musculoskeletal diseases that are manifested in adulthood (Hernandez et al. 2003; Kuh et al. 2006). We and others have previously reported that school-based exercise interventions can enhance bone mineral accrual in both young boys and girls (Bradney et al. 1998; Fuchs et al. 2001; Linden et al. 2007; MacKelvie et al. 2003; Mackelvie et al. 2001; MacKelvie et al. 2004; Morris et al. 1997; Valdimarsson et al. 2006). In this study, we report that a moderate intensity school based general physical activity program involving activities such as ball games, running, jumping, gymnastics activities and climbing, was also effective for improving muscle strength development in young girls. These findings are consistent with the results from a 10 month non-randomised controlled intervention in which premenarcheal girls aged 9-10 years participated in a school based exercise program that was performed three days per week (30 minute sessions) and involved activities such as aerobics, modified soccer and Australian Rules football, bush and modern dancing, skipping, ball games and resistance training (Morris et al. 1997). In this study, the authors reported that the rates of change in shoulder and knee extension isokinetic peak torque and grip strength were 7 to $33 \%$ greater in the exercise relative to control group. The greater exercise-induced gains in muscle strength in this latter study are likely due to the inclusion of a specific resistance training circuit program into the intervention. However, it is also possible that part of the between group differences were due to variations in the maturity progression of the girls in the exercise relative to control group. In our study all girls remained pre-pubertal from baseline to 
follow-up, and the greater increases in muscle strength in the exercise group were independent of baseline measures and organised physical activity outside of school, which implies that the increases in muscle strength in the intervention group girls were due to the school-based physical activity program.

Training-induced increases in muscle strength during growth can be attributed to neuromuscular adaptations in conjunction with increases in muscle mass or size, which is often enhanced during puberty by an increase in the secretion of sex steroids (Blimkie 1993; Malina et al. 2004). However, most studies involving pre-pubertal children suggest that any gains in muscle strength in response to training are due primarily to neural adaptations (Blimkie 1993; Ramsay et al. 1990; Weltman et al. 1986). In this study, we observed that the increases in muscle strength were independent of the changes in lean tissue mass. This suggests that other factors contributed to the increase in the force producing capacity of muscle in the pre-pubertal girls. It has been suggested that gains in muscle strength during growth are also due to changes in a number of neural factors, including enhanced motor unit activation, co-ordination, recruitment and/or firing frequency (Faigenbaum et al. 1999; Ozmun et al. 1994; Ramsay et al. 1990). However, further studies are needed to define the neural adaptations that occur in response to physical training in both prepubertal boys and girls.

There have been few long-term studies that have investigated the effect of regular physical training on muscle mass or size in prepubertal boys or girls. Many of the early studies that examined the effect of resistance training on muscle hypertrophy in children were of short duration ( $<8$ weeks) and relied on estimates of muscle mass or size (eg. limb circumference) (Malina et al. 2004). Using DXA to measure lean tissue mass, which has shown to be comparable to criterion in vivo techniques (Sopher et al. 2004; Wong et al. 2002), we observed that the 12 month school based physical activity program led to a 1.9 to $3.4 \%$ per year greater increase in total body and leg lean tissue mass in the exercise relative to control group. These findings are consistent with the results from a recent 6 year longitudinal study in boys and girls which found that those in the upper quintile of general habitual physical activity gain 3 to $6 \%$ more lean mass than those at the lowest quintile, depending on age and gender (Baxter-Jones 
et al. 2008; Lohman 2008). Given that the girls in our study did not participate in a specific resistance training program, we hypothesize that the exercise-induced gains in lean tissue mass were related to the relatively large increase in training volume (from 60 to 200 minutes per week) coupled with the long study duration (12 months). In part support of this hypothesis, we found that the total duration of physical activity was positively related to changes in muscle strength in all girls. Furthermore, the results from an 8 week resistance training trial in children showed that high repetition-moderate load (high volume training) led to greater gains in muscle strength than low repetition-high load (low volume) resistance training (Faigenbaum et al. 1999). It is also possible that the positive effect of the intervention on both lean tissue mass and muscle strength in our study were related to the relatively low baseline physical activity levels in the girls; the average time spent participating in organised physical activity outside of school was 60 minutes per week, but $60 \%$ of the girls in the exercise intervention group did not participate in any organised physical activity outside of school at baseline.

Despite reports that resistance and/or general physical training can enhance muscle strength in children, there are conflicting reports as to whether these benefits translate into improvements in other physical performance tasks (athletic performance, VJH, long jump, sprint speed) (Faigenbaum et al. 1999; Ingle et al. 2006; Lillegard et al. 1997; Weltman et al. 1986). When we examined the effect of the intervention on VJH in the girls, there was a marked improvement in the exercise relative to control group (12.5 versus 3.2\% per year), but the between group difference did not persist after adjusting for baseline age and VJH and organised physical activity outside of school at follow-up [mean adjusted difference, 4.1\% (95\% CI: -3.7, 12.0)]. This lack of a statistically significant effect of the intervention on vertical jump performance is consistent with the results from a 20 month schoolbased exercise trial which reported a non significant difference but trend toward a greater improvement in the exercise compared to control girls for both VJH $(\sim 10 \%, \mathrm{p}=0.14)$ and long jump ( $\sim 3 \%, p=0.10$ ) (MacKelvie et al. 2003). The lack of a significant difference in VJH in our study could be explained by the non-specific nature of the training program and/or the inability of this test to accurately capture changes in functional performance. The school based intervention consisted of a 
diverse range of physical activities, and since changes in VJH are believed to reflect neuromuscular adaptations (Myer et al. 2005), it would appear that these activities did not specifically replicate the vertical jump movement pattern and thus were not sufficient to significantly improve jumping performance.

An unexpected finding in our study was the greater annual gain in fat mass in the intervention group compared with the controls, a discrepancy we are unable to explain. However, others have also reported an increase in fat mass in children, despite increased physical training (Treuth et al. 1998). For example, Treuth et al. (Treuth et al. 1998) reported increases in arms, legs, trunk and total body fat mass and lean mass over a 5 month period in prepubertal girls randomised to a strength training intervention, but these changes were not significantly different from the control group. The greater gain in fat mass in the intervention group in the present study could be explained by an increased appetite and an increased food intake accompanying the increased duration of exercise. Although we did not assess dietary habits, we have previously reported that the discrepancy in fat gain was most likely the result of other influences besides physical activity, because there was no dose-response relationship between the duration of activity and gain in fat mass (Linden et al. 2007).

There are a number of limitations with this study. First, the trial was not a randomised controlled study, and thus the findings may be influenced by selection bias and do not provide the highest level of evidence upon which recommendations can be made. However, randomisation was not possible because the principals, teachers, parents and children made it clear that it was neither feasible nor practical for some children to be given additional physical activity during compulsory school hours while others were not. A randomisation of the school, even if not a true randomisation, would have been preferable in order to reduce the risk of selection bias, but because we did not include an intervention school with a high duration of physical activity at baseline, and since all schools had a similar amount of regular school physical education prior to the commencement of the study, we decided that the best approach would be to modify the current curriculum in order to increase physical activity levels within a school; this reduced the risk of introducing selection bias based on the choice 
of the intervention school. A randomisation within the classes was not considered as this would, over time, have led to problems with children crossing over between the groups. Second, due to lack of resources in our research laboratory, control group girls were remeasured after two years. However, as all the girls remained prepubertal (Tanner stage I) during the study period, it was possible to compare the annual changes between the groups as there is evidence that the development of quadriceps strength is proportional to the gains in height and weight during this period (Round et al. 1999). This view is supported by Swedish data which has shown that the rate of growth is linear from age 6 to peak height velocity and that only 5.6\% of girls reach peak height velocity at age 10 years (Liu et al. 2000). The average age of peak height velocity for Swedish girls is 11.7 years. Thus, based on the fact that we followed girls aged, on average 7.8 years, and who all remained in Tanner stage I, it is unlikely that any of the observed differences in body composition or muscle strength were related to difference in the follow-up duration between the intervention and control group. Third, the estimate of lean tissue mass and fat mass was made using DXA. Even though this technique is comparable to criterion in vivo techniques (Sopher et al. 2004; Wong et al. 2002), it has been shown that DXA-based body composition measures during growth can be influenced by differences in hydration status, body size (or tissue depth), and fat distribution (Formica 1999). Further studies using advanced imaging techniques [MRI or (p)QCT] are needed to assess the influence of physical training on muscle and fat cross-sectional area, and the relationship with muscle strength in children. Finally, physical activity habits were assessed by questionnaire and were limited to an evaluation of school and organised physical activity only; no data was collected on leisure-time physical activity.

In conclusion, the findings from this 12 month school based intervention trial demonstrate that increasing the amount of moderate intensity physical education in the school curriculum to at least 3 hours per week provides a feasible strategy to increase overall physical activity levels and enhance muscle strength and lean tissue mass in prepubertal girls. These findings have important clinical implications because there is a growing body of evidence which suggests that the first two decades of life may represent the most opportune time to reduce the risk of a number of chronic musculoskeletal health conditions in later life, including osteoporosis and related fracture (Hernandez et al. 2003). 
Importantly, our program was designed to enable ordinary school teachers to lead the physical education classes, which did not require any additional resources or external support. The only change from the standard Swedish PE curriculum was an increase in the frequency of the classes. Thus, the findings from this study and our previous work provide further evidence to support the health benefits of school-based physical activity for young children. However, we must await the outcome of further long-term, school-based randomised controlled trials which are adequately powered before we can define precise exercise prescription guidelines for optimising muscle health and function during growth. 
Figure 1: Mean annual changes in the weight adjusted knee extension (Ex) and flexion (Fl) peak torque (PT) at $60^{\circ} / \mathrm{sec}$ and $180^{\circ} / \mathrm{sec}$ and vertical jump height $(\mathrm{VJH})$ in the intervention and control group. All data represents the annual changes adjusted for baseline age, peak torque (or VJH) and organised physical activity outside of school at follow-up. ${ }^{*} \mathrm{p}<0.05, \ddagger \mathrm{p}<0.001$ versus control group. 


\section{References}

Bass S, Pearce G, Bradney M, Hendrich E, Delmas PD, Harding A, Seeman E (1998) Exercise before puberty may confer residual benefits in bone density in adulthood: studies in active prepubertal and retired female gymnasts. J Bone Miner Res 13: 500-507

Baxter-Jones AD, Eisenmann JC, Mirwald RL, Faulkner RA, Bailey DA (2008) The influence of physical activity on lean mass accrual during adolescence: a longitudinal analysis. J Appl Physiol 105: 734-741

Blimkie CJ (1993) Resistance training during preadolescence. Issues and controversies. Sports Med 15: 389-407

Bradney M, Pearce G, Naughton G, Sullivan C, Bass S, Beck T, Carlson J, Seeman E (1998) Moderate exercise during growth in prepubertal boys: changes in bone mass, size, volumetric density, and bone strength: a controlled prospective study. J Bone Miner Res 13: 1814-1821

Daly RM, Saxon L, Turner CH, Robling AG, Bass SL (2004) The relationship between muscle size and bone geometry during growth and in response to exercise. Bone 34: 281-287

De Ste Croix M, Deighan M, Armstrong N (2003) Assessment and interpretation of isokinetic muscle strength during growth and maturation. Sports Med 33: 727-743

De Ste Croix MBA, Armstrong N, Welsman JR (1999) Concentric isokinetic leg strength in pre-teen, teenage and adult males and females. Biol Sport 16: 75-86

Dencker M, Thorsson O, Karlsson MK, Linden C, Eiberg S, Wollmer P, Andersen LB (2006) Daily physical activity related to body fat in children aged 8-11 years. J Pediatr 149: 38-42

Duppe H, Gardsell P, Johnell O, Nilsson BE, Ringsberg K (1997) Bone mineral density, muscle strength and physical activity. A population-based study of 332 subjects aged 15-42 years. Acta Orthop Scand 68: 97-103

Ellenbecker TS, Roetert EP, Riewald S (2006) Isokinetic profile of wrist and forearm strength in elite female junior tennis players. Br J Sports Med 40: 411-414 
Faigenbaum AD, Westcott WL, Loud RL, Long C (1999) The effects of different resistance training protocols on muscular strength and endurance development in children. Pediatrics 104: e5

Formica CA (1999) Total body bone mineral and body composition by absorptiomery. In: Blake GM, Wahner HW, Fogelholm GM (eds) The evaluation of osteoporosis: dual energy X-ray absorptiometry and ultrasound in clinical practice. Martin Dunitz, London, pp. 313-345

Fuchs RK, Bauer JJ, Snow CM (2001) Jumping improves hip and lumbar spine bone mass in prepubescent children: a randomized controlled trial. J Bone Miner Res 16: 148-156

Hernandez CJ, Beaupre GS, Carter DR (2003) A theoretical analysis of the relative influences of peak BMD, age-related bone loss and menopause on the development of osteoporosis. Osteoporos Int 14: $843-847$

Ingle L, Sleap M, Tolfrey K (2006) The effect of a complex training and detraining programme on selected strength and power variables in early pubertal boys. J Sports Sci 24: 987-997

Kanehisa H, Ikegawa S, Tsunoda N, Fukunaga T (1995) Strength and cross-sectional areas of reciprocal muscle groups in the upper arm and thigh during adolescence. Int J Sports Med 16: 5460

Kanehisa H, Kuno S, Katsuta S, Fukunaga T (2006) A 2-year follow-up study on muscle size and dynamic strength in teenage tennis players. Scandinavian journal of medicine \& science in sports 16: $93-101$

Kuh D, Hardy R, Butterworth S, Okell L, Wadsworth M, Cooper C, Aihie Sayer A (2006) Developmental origins of midlife grip strength: findings from a birth cohort study. J Gerontol A Biol Sci Med Sci 61: 702-706

Lillegard WA, Brown EW, Wilson DJ, Henderson R, Lewis E (1997) Efficacy of strength training in prepubescent to early postpubescent males and females: effects of gender and maturity. Pediatr Rehabil 1: 147-157

Linden C, Alwis G, Ahlborg H, Gardsell P, Valdimarsson O, Stenevi-Lundgren S, Besjakov J, Karlsson MK (2007) Exercise, bone mass and bone size in prepubertal boys: one-year data from 
the pediatric osteoporosis prevention study. Scandinavian journal of medicine \& science in sports 17: $340-347$

Liu YX, Wikland KA, Karlberg J (2000) New reference for the age at childhood onset of growth and secular trend in the timing of puberty in Swedish. Acta Paediatr 89: 637-643

Lohman TG (2008) Six-year longitudinal analysis shows physical activity impacts on lean mass development in adolescence. J Appl Physiol 105: 403

MacKelvie KJ, Khan KM, Petit MA, Janssen PA, McKay HA (2003) A school-based exercise intervention elicits substantial bone health benefits: a 2-year randomized controlled trial in girls. Pediatrics 112: e447

Mackelvie KJ, McKay HA, Khan KM, Crocker PR (2001) A school-based exercise intervention augments bone mineral accrual in early pubertal girls. J Pediatr 139: 501-508

MacKelvie KJ, Petit MA, Khan KM, Beck TJ, McKay HA (2004) Bone mass and structure are enhanced following a 2-year randomized controlled trial of exercise in prepubertal boys. Bone 34: 755-764

Malina R, Bouchard C, Bar-Or O (2004) Growth, maturation and physical activity. Human Kinetics, Champaign, IL

Matthews BL, Bennell KL, McKay HA, Khan KM, Baxter-Jones AD, Mirwald RL, Wark JD (2006) Dancing for bone health: a 3-year longitudinal study of bone mineral accrual across puberty in female non-elite dancers and controls. Osteoporos Int 17: 1043-1054

Morris FL, Naughton GA, Gibbs JL, Carlson JS, Wark JD (1997) Prospective ten-month exercise intervention in premenarcheal girls: positive effects on bone and lean mass. J Bone Miner Res 12: $1453-1462$

Myer GD, Ford KR, Palumbo JP, Hewett TE (2005) Neuromuscular training improves performance and lower extremity biomechanics in female athletes. J Strength Cond Res 19: 51-60 
Ozmun JC, Mikesky AE, Surburg PR (1994) Neuromuscular adaptations following prepubescent strength training. Med Sci Sports Exerc 26: 510-514

Ramsay JA, Blimkie CJ, Smith K, Garner S, MacDougall JD, Sale DG (1990) Strength training effects in prepubescent boys. Med Sci Sports Exerc 22: 605-614

Round JM, Jones DA, Honour JW, Nevill AM (1999) Hormonal factors in the development of differences in strength between boys and girls during adolescence: a longitudinal study. Ann Hum Biol 26: 49-62

Sopher AB, Thornton JC, Wang J, Pierson RN, Jr., Heymsfield SB, Horlick M (2004) Measurement of percentage of body fat in 411 children and adolescents: a comparison of dual-energy X-ray absorptiometry with a four-compartment model. Pediatrics 113: 1285-1290

Sothern MS, Loftin M, Suskind RM, Udall JN, Blecker U (1999) The health benefits of physical activity in children and adolescents: implications for chronic disease prevention. Eur J Pediatr 158: $271-274$

Treuth MS, Hunter GR, Figueroa-Colon R, Goran MI (1998) Effects of strength training on intraabdominal adipose tissue in obese prepubertal girls. Med Sci Sports Exerc 30: 1738-1743

Valdimarsson O, Linden C, Johnell O, Gardsell P, Karlsson MK (2006) Daily physical education in the school curriculum in prepubertal girls during 1 year is followed by an increase in bone mineral accrual and bone width--data from the prospective controlled Malmo pediatric osteoporosis prevention study. Calcif Tissue Int 78: 65-71

Weltman A, Janney C, Rians CB, Strand K, Berg B, Tippitt S, Wise J, Cahill BR, Katch FI (1986) The effects of hydraulic resistance strength training in pre-pubertal males. Med Sci Sports Exerc 18: 629-638

Wong WW, Hergenroeder AC, Stuff JE, Butte NF, Smith EO, Ellis KJ (2002) Evaluating body fat in girls and female adolescents: advantages and disadvantages of dual-energy X-ray absorptiometry. Am J Clin Nutr 76: 384-389 
Young D, Hopper JL, Macinnis RJ, Nowson CA, Hoang NH, Wark JD (2001) Changes in body composition as determinants of longitudinal changes in bone mineral measures in 8 to 26-year-old female twins. Osteoporos Int 12: 506-515

Zanchetta JR, Plotkin H, Alverez Filgueira ML (1995) Bone mass in children: normative values for the 2-20 year-old population. Bone 16: 395S-399S 


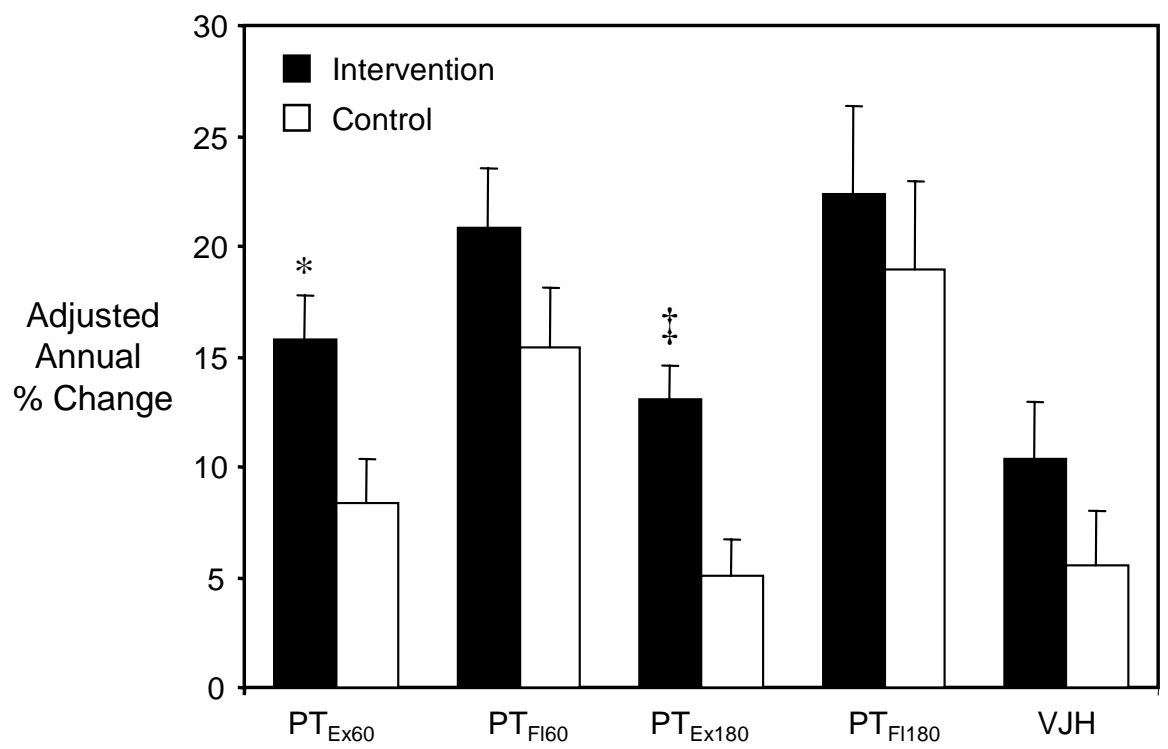


Table 1: Comparison of the anthropometric, body composition, muscle force measures and vertical jump height between girls classified as active and sedentary girls at baseline.

\begin{tabular}{|c|c|c|c|}
\hline Characteristics & $\begin{array}{l}\text { Active } \\
(\mathrm{n}=69)\end{array}$ & $\begin{array}{l}\text { Sedentary } \\
\quad(n=34)\end{array}$ & P-value \\
\hline Age (years) & $7.8 \pm 0.6$ & $7.6 \pm 0.5$ & $=0.05$ \\
\hline Height $(\mathrm{cm})^{a}$ & $128.3 \pm 6.8$ & $129.0 \pm 6.2$ & 0.07 \\
\hline Physical activity (hr/wk) & $1.5 \pm 1.5$ & 0.0 & $<0.001$ \\
\hline \multicolumn{4}{|l|}{ Body composition ${ }^{a}$} \\
\hline Weight (kg) & $26.9 \pm 5.1$ & $28.5 \pm 6.2$ & 0.09 \\
\hline $\operatorname{BMI}\left(\mathrm{kg} / \mathrm{m}^{2}\right)$ & $16.3 \pm 2.3$ & $17.0 \pm 2.8$ & 0.25 \\
\hline \% Total body fat & $18.3 \pm 8.2$ & $20.9 \pm 9.1$ & 0.20 \\
\hline \multicolumn{4}{|l|}{ Lean mass (kg) } \\
\hline Total body & $19.8 \pm 2.4$ & $20.4 \pm 2.7$ & 0.06 \\
\hline Legs & $6.3 \pm 1.1$ & $6.4 \pm 1.1$ & 0.14 \\
\hline Arms & $1.6 \pm 0.3$ & $1.7 \pm 0.3$ & 0.09 \\
\hline \multicolumn{4}{|l|}{ Fat mass (kg) } \\
\hline Total body & $4.9 \pm 3.3$ & $5.9 \pm 4.1$ & 0.17 \\
\hline Leg & $2.1 \pm 1.1$ & $2.5 \pm 1.3$ & 0.14 \\
\hline Arms & $0.5 \pm 0.5$ & $0.6 \pm 0.5$ & 0.45 \\
\hline \multicolumn{4}{|l|}{ Peak Torque $(\mathrm{Nm} / \mathrm{kg})^{a}$} \\
\hline $\mathrm{PT}_{\mathrm{Ex60}}$ & $1.61 \pm 0.28$ & $1.49 \pm 0.28$ & 0.13 \\
\hline $\mathrm{PT}_{\mathrm{Fl60}}$ & $0.83 \pm 0.15$ & $0.74 \pm 0.19$ & $<0.05$ \\
\hline $\mathrm{PT}_{\mathrm{Ex} 180}$ & $1.27 \pm 0.20$ & $1.18 \pm 0.25$ & 0.18 \\
\hline $\mathrm{PT}_{\mathrm{F} 1180}$ & $0.75 \pm 0.15$ & $0.67 \pm 0.19$ & 0.11 \\
\hline \multicolumn{4}{|l|}{ Physical Performance ${ }^{a}$} \\
\hline Vertical jump height (cm) & $22.2 \pm 3.7$ & $20.9 \pm 3.7$ & 0.19 \\
\hline
\end{tabular}

All values represent unadjusted means $\pm \mathrm{SD} .{ }^{a}$ ANCOVA adjusted age. 
Table 2. Baseline data and the annual unadjusted absolute changes in height, body composition, muscle force and vertical jump height in the intervention and control group.

\begin{tabular}{|c|c|c|c|c|}
\hline & \multicolumn{2}{|c|}{ Baseline } & \multicolumn{2}{|c|}{ Mean Annual Changes (95\% CI) } \\
\hline & $\begin{array}{l}\text { Intervention } \\
\qquad(n=53)\end{array}$ & $\begin{array}{l}\text { Control } \\
(n=50)\end{array}$ & $\begin{array}{l}\text { Intervention } \\
\qquad(\mathrm{n}=53)\end{array}$ & $\begin{array}{l}\text { Control } \\
(n=50)\end{array}$ \\
\hline Age (years) & $7.7 \pm 0.6$ & $7.9 \pm 0.6$ & & \\
\hline Height (cm) & $128.8 \pm 5.2$ & $129.1 \pm 7.9$ & $6.0(5.6,6.3)$ & $5.7(5.4,6.0)$ \\
\hline \multicolumn{5}{|l|}{ Body composition $^{a}$} \\
\hline Weight (kg) & $27.6 \pm 5.5$ & $27.4 \pm 5.5$ & $3.5(2.9,4.2)$ & $3.2(2.9,3.6)$ \\
\hline BMI $\left(\mathrm{kg} / \mathrm{m}^{2}\right)$ & $16.8 \pm 2.9$ & $16.3 \pm 1.9$ & $0.5(0.2,0.8)$ & $0.4(0.2,0.5)$ \\
\hline$\%$ Total body fat & $19.3 \pm 9.5$ & $19.0 \pm 7.4$ & $3.4(2.7,4.1) \ddagger$ & $1.3(0.9,1.7)$ \\
\hline \multicolumn{5}{|l|}{ Lean mass (kg) } \\
\hline Total body & $19.8 \pm 2.3$ & $20.2 \pm 2.8$ & $2.2(2.0,2.4) *$ & $1.9(1.7,2.0)$ \\
\hline Legs & $6.3 \pm 1.0$ & $6.4 \pm 1.2$ & $1.1(1.0,1.2) \dagger$ & $0.9(0.8,0.9)$ \\
\hline Arms & $1.6 \pm 0.3$ & $1.7 \pm 0.3$ & $0.3(0.2,0.3) \ddagger$ & $0.2(0.16,0.21)$ \\
\hline \multicolumn{5}{|l|}{ Fat mass (kg) } \\
\hline Total body & $5.3 \pm 3.9$ & $5.2 \pm 3.3$ & $1.9(1.5,2.3) \dagger$ & $1.0(0.8,1.3)$ \\
\hline Legs & $2.2 \pm 1.2$ & $2.2 \pm 1.1$ & $0.8(0.6,0.9) \dagger$ & $0.5(0.4,0.6)$ \\
\hline Arms & $0.5 \pm 0.5$ & $0.5 \pm 0.5$ & $0.2(0.1,0.3) \dagger$ & $0.06(0.0,0.1)$ \\
\hline \multicolumn{5}{|l|}{ Peak Torque ${ }^{b}$} \\
\hline \multicolumn{5}{|l|}{ Unadjusted (Nm) } \\
\hline $\mathrm{PT}_{\mathrm{Ex} 60}$ & $40.9 \pm 9.3$ & $44.9 \pm 10.6$ & $13.5(10.4,16.6) \dagger$ & $8.5(7.4,9.7)$ \\
\hline $\mathrm{PT}_{\mathrm{Fl60}}$ & $19.5 \pm 4.9 \ddagger$ & $24.3 \pm 6.0$ & $7.5(6.3,8.7) *$ & $5.0(4.0,6.1)$ \\
\hline $\mathrm{PT}_{\mathrm{Ex} 180}$ & $32.0 \pm 7.7 \#$ & $35.7 \pm 7.3$ & $8.8(7.5,10.1) \ddagger$ & $5.7(5.0,6.5)$ \\
\hline $\mathrm{PT}_{\mathrm{Fl} 180}$ & $17.4 \pm 4.8 \ddagger$ & $21.8 \pm 4.6$ & $7.3(5.9,8.7) \dagger$ & $4.1(3.2,5.0)$ \\
\hline \multicolumn{5}{|l|}{ Weight adjusted (Nm/kg) } \\
\hline $\mathrm{PT}_{\mathrm{Ex} 60}$ & $1.50 \pm 0.30 \#$ & $1.64 \pm 0.24$ & $0.22(0.14,0.30) *$ & $0.10(0.07,0.13)$ \\
\hline $\mathrm{PT}_{\mathrm{Fl} 60}$ & $0.71 \pm 0.16 \ddagger$ & $0.89 \pm 0.14$ & $0.17(0.12,0.21)$ & $0.07(0.04,0.10)$ \\
\hline $\mathrm{PT}_{\mathrm{Ex} 180}$ & $1.17 \pm 0.25 \dagger$ & $1.31 \pm 0.16$ & $0.15(0.11,0.20) \ddagger$ & $0.05(0.03,0.06)$ \\
\hline $\mathrm{PT}_{\text {Fl180 }}$ & $0.64 \pm 0.16 \ddagger$ & $0.80 \pm 0.12$ & $0.16(0.12,0.21)$ & $0.05(0.02,0.07)$ \\
\hline \multicolumn{5}{|l|}{ Physical Performance ${ }^{c}$} \\
\hline Vertical jump height (cm) & $20.7 \pm 3.6 \dagger$ & $22.8 \pm 3.6$ & $2.2(0.9,3.5)$ & $0.6(0.1,1.1)$ \\
\hline
\end{tabular}

All values represent means \pm SD and unadjusted changes (95\% CI). \# p=0.06, * $\mathrm{p}=0.05, \dagger \mathrm{p}<0.01, \ddagger \mathrm{p}<0.001 \mathrm{vs}$ controls. All baseline comparison adjusted for age; ${ }^{a}$ annual changes adjusted for baseline age and organised physical activity outside of school at follow-up; ${ }^{\mathrm{b}}$ annual changes adjusted for baseline age, peak torque, and organised physical activity outside of school at follow-up; ${ }^{c}$ annual changes adjusted for baseline age, vertical jump height and organised physical activity outside of school at follow-up. 